The Journal of Nonlinear $\mathbf{S}$ ciences and Applications

http://www.tjnsa.com

\title{
CONVERGENCE OF FIXED POINT OF ASYMPTOTICALLY QUASI-NONEXPANSIVE TYPE MAPPINGS IN CONVEX METRIC SPACES
}

\author{
GURUCHARAN SINGH SALUJA
}

\begin{abstract}
In this paper, we give some necessary and sufficient conditions for three-step iterative sequence with errors for asymptotically quasi-nonexpansive type mapping converging to a fixed point in convex metric spaces. The results presented in this paper extend the corresponding results of Kim et al. [9, 10 and many others. Also the corresponding results in $1,1,2,3,6,12,13,14,16,18,20$. are spcial cases of our results.
\end{abstract}

\section{INTRODUCTION AND PRELIMINARIES}

Throughout this paper, we assume that $E$ is a metric space, $F(T)$ and $D(T)$ are the set of fixed points and domain of $T$ respectively and $\mathbb{N}$ is the set of all positive integers.

Definition 1.1 ( [4]): Let $T: D(T) \subset E \rightarrow E$ be a mapping.

(1) The mapping $T$ is said to be $L$-Lipschitzian if there exists a constant $L>0$ such that

$$
d(T x, T y) \leq L . d(x, y), \quad \forall x, y \in D(T)
$$

Date: Received: 16 October 2008.

2000 Mathematics Subject Classification. 47H05, 47H09, 49M05.

Key words and phrases. Asymptotically nonexpansive mapping, asymptotically nonexpansive type mapping, asymptotically quasi-nonexpansive type mapping, convex metric space, fixed point, three-step iterative process with errors. 
(2) The mapping $T$ is said to be nonexpansive if

$$
d(T x, T y) \leq d(x, y), \quad \forall x, y \in D(T)
$$

(3) The mapping $T$ is said to be quasi-nonexpansive if $F(T) \neq \emptyset$ and

$$
d(T x, p) \leq d(x, p), \quad \forall x \in D(T), \forall p \in F(T) .
$$

(4) The mapping $T$ is said to be asymptotically nonexpansive if there exists a sequence $k_{n} \in[1, \infty)$ with $\lim _{n \rightarrow \infty} k_{n}=1$ such that

$$
d\left(T^{n} x, T^{n} y\right) \leq k_{n} d(x, y), \quad \forall x, y \in D(T), \forall n \in \mathbb{N}
$$

(5) The mapping $T$ is said to be asymptotically quasi-nonexpansive if $F(T) \neq \emptyset$ and there exists a sequence $k_{n} \in[1, \infty)$ with $\lim _{n \rightarrow \infty} k_{n}=1$ such that

$$
d\left(T^{n} x, p\right) \leq k_{n} d(x, p), \quad \forall x \in D(T), \forall p \in F(T), \forall n \in \mathbb{N}
$$

(6) $T$ is said to be asymptotically nonexpansive type, if

$$
\limsup _{n \rightarrow \infty}\left\{\sup _{x, y \in D(T)}\left\{d\left(T^{n} x, T^{n} y\right)-d(x, y)\right\}\right\} \leq 0
$$

(7) $T$ is said to be asymptotically quasi-nonexpansive type, if $F(T) \neq \emptyset$ and

$$
\limsup _{n \rightarrow \infty}\left\{\sup _{x \in D(T), p \in F(T)}\left\{d\left(T^{n} x, p\right)-d(x, p)\right\}\right\} \leq 0,
$$

Remark 1.1: It is easy to see that if $F(T)$ is nonempty, then nonexpansive mapping, quasi-nonexpansive mapping, asymptotically nonexpansive mapping, asymptotically quasi-nonexpansive mapping and asymptotically nonexpansive type mapping all are the special cases of asymptotically quasi-nonexpansive type mapping.

In recent years, the problem concerning convergence of iterative sequences (and sequences with errors) for asymptotically nonexpansive mappings or asymptotically quasi-nonexpansive mappings converging to some fixed points in Hilbert spaces or Banach spaces have been considered by many authers. 
In 1973, Petryshyn and Williamson [16] obtained a necessary and sufficient condition for Picard iterative sequences and Mann iterative sequences to converge to a fixed point for quasi-nonexpansive mappings. In 1994, Tan and Xu [20] also proved some convergence theorems of Ishikawa iterative sequences satisfies Opial's condition or has a Frechet differential norm. In 1997, Ghosh and Debnath 6] extended the result of Petryshyn and Williamson [16] and gave a necessary and sufficient condition for Ishikawa iterative sequences to converge to a fixed point of quasi-nonexpansive mappings. In 2001, in [1, 2, 3] the auther proved some another kinds of necessary and sufficient conditions for Ishikawa iterative sequences with errors for asymptotically nonexpansive mappings to converge to a fixed point. Also in 2001 and 2002, Liu [12, 13, 14] obtained some necessary and sufficient conditions for Ishikawa iterative sequences or Ishikawa iterative sequences with errors to converge to a fixed point for asymptotically quasi-nonexpansive mappings.

In 2000, Noor [15] introduced a three step iterative scheme and studied the approximate solution of variational inclusion in Hilbert spaces by using the techniques of updating the solution and auxiliary principle. Glowinski and Le Tallec [7] used three step iterative schemes to find the approximate solution of the elastoviscoplasticity problem, liquid crystal theory, and eigenvalue computation. It has been shown [7] that three step iterative scheme gives better numerical results than the two step and one step approximate iterations. Thus we conclude that three step scheme plays an important and significant role in solving various problems, which arise in pure and applied sciences. Recently, Xu and Noor [18] introduced and studies a three step scheme to approximate fixed points of asymptotically nonexpansive mappings in Banach space. In 2004, Cho et al. [5] extended the work of $\mathrm{Xu}$ and Noor 18 to the three step iterative scheme with errors in Banach space and gave weak and strong convergence theorems for asymptotically nonexpansive mappings in a Banach space. In 2004, Kim et al. [10] gave the necessary and sufficient conditions for asymptotically quasi-nonexpansive mappings in convex metric spaces and generalized and improved some previous known results.

The purpose of this paper is to study the convergence problem of three-step iterative sequences with errors for asymptotically quasi-nonexpansive type mappings in convex metric spaces and give some necessary and sufficient conditions to converge to fixed point for above said mappings. The results presented in the paper extend and improve the corresponding results of Liu [12, 13, 14], Ghosh and Debnath [6], Petryshyn and Williamson [16], Tan and Xu [20], Chang [1]- [3] and Kim et al. [10]. Our results also contain the corresponding results of [1][6], [12]- [16], [4], [18] as its special cases.

For the sake of convenience, we first recall some definitions and notations.

Definition 1.2: Let $(E, D)$ be a metric space and $I=[0,1]$. A mapping $W: E^{3} \times I^{3} \rightarrow E$ is said to be a convex structure on $E$ if it satisfies the following condition: 


$$
d(u, W(x, y, z ; \alpha, \beta, \gamma)) \leq \alpha d(u, x)+\beta d(u, y)+\gamma d(u, z)
$$

for any $u, x, y, z \in E$ and for any $\alpha, \beta, \gamma \in I$ with $\alpha+\beta+\gamma=1$.

If $(E, d)$ is a metric space with a convex structure $W$, then $(E, d)$ is called a convex metric space and denotes it by $(E, d, W)$.

Remark 1.2: It is easy to prove that every linear normed space is a convex metric space with a convex structure $W(x, y, z ; \alpha, \beta, \gamma)=\alpha x+\beta y+\gamma z$, for all $x, y, z \in E$ and $\alpha, \beta, \gamma \in I$ with $\alpha+\beta+\gamma=1$. But there exist some convex metric spaces which can not be embedded into any linear normed spaces (see, Takahashi [17]).

Definition 1.3: Let $(E, d, W)$ be a convex metric space, $T: E \rightarrow E$ be an asymptotically quasi-nonexpansive type mapping and let $x_{0} \in E$ be a given point. Then the sequence $\left\{x_{n}\right\}$ defined by

$$
\begin{aligned}
x_{n+1} & =W\left(x_{n}, T^{n} y_{n}, u_{n} ; a_{n}, b_{n}, c_{n}\right), \\
y_{n} & =W\left(x_{n}, T^{n} z_{n}, v_{n} ; a_{n}^{\prime}, b_{n}^{\prime}, c_{n}^{\prime}\right), \\
z_{n} & =W\left(x_{n}, T^{n} x_{n}, w_{n} ; a_{n}^{\prime \prime}, b_{n}^{\prime \prime}, c_{n}^{\prime \prime}\right), \quad n \geq 0,
\end{aligned}
$$

is called the three-step iterative sequence with errors for the mapping $T$, where $\left\{a_{n}\right\},\left\{a_{n}^{\prime}\right\},\left\{a_{n}^{\prime \prime}\right\},\left\{b_{n}\right\},\left\{b_{n}^{\prime}\right\},\left\{b_{n}^{\prime \prime}\right\},\left\{c_{n}\right\},\left\{c_{n}^{\prime}\right\}$ and $\left\{c_{n}^{\prime \prime}\right\}$ are nine sequences in $[0,1]$ satisfying the following conditions:

$$
a_{n}+b_{n}+c_{n}=a_{n}^{\prime}+b_{n}^{\prime}+c_{n}^{\prime}=a_{n}^{\prime \prime}+b_{n}^{\prime \prime}+c_{n}^{\prime \prime}=1, \forall n \geq 0,
$$

and $\left\{u_{n}\right\},\left\{v_{n}\right\},\left\{w_{n}\right\}$ are three bounded sequences in $E$.

In order to prove our main theorem of this paper, we need the following lemma:

Lemma 1.1 [19]: Let $\left\{a_{n}\right\},\left\{b_{n}\right\}$ be sequences of nonnegative real numbers satisfying the inequality

$$
a_{n+1} \leq a_{n}+b_{n}, \quad n \geq 1
$$

If $\sum_{n=1}^{\infty} b_{n}<\infty$. Then

(a) $\lim _{n \rightarrow \infty} a_{n}$ exists. 
(b) If $\liminf _{n \rightarrow \infty} a_{n}=0$, then $\lim _{n \rightarrow \infty} a_{n}=0$.

\section{MAin RESUlts}

In order to prove our main result, we will first prove the following important lemma.

Lemma 2.1: Let $(E, d, W)$ be a convex metric space, $T: E \rightarrow E$ be an asymptotically quasi-nonexpansive type mapping. For any given $x_{0} \in E$, let $\left\{x_{n}\right\}$ be the three-step iterative sequence with errors defined by (1.2). If the sequences $\left\{b_{n}\right\}$ and $\left\{c_{n}\right\}$ appeared in (1.7) satisfying the following conditions:

(i) $\sum_{n=1}^{\infty} b_{n}<\infty$,

(ii) $\sum_{n=1}^{\infty} c_{n}<\infty$.

Then

(a) For any given $\varepsilon>0$, there exists a positive integer $n_{0}$ and $M>0$ such that

$$
d\left(x_{n+1}, p\right) \leq d\left(x_{n}, p\right)+M b_{n}+c_{n} d\left(u_{n}, p\right), \quad \forall p \in F(T), \quad n \geq n_{0},
$$

(b) $d\left(x_{n+m}, p\right) \leq d\left(x_{n}, p\right)+M \sum_{k=n}^{n+m-1} b_{k}+\sum_{k=n}^{n+m-1} c_{k} d\left(u_{k}, p\right), \forall p \in F(T)$, $n \geq n_{0}, \forall m \geq 1$, where

$$
M=3 \varepsilon+\sup _{n \geq 0} d\left(v_{n}, p\right)+\sup _{n \geq 0} d\left(w_{n}, p\right)<\infty
$$

(c) $\lim _{n \rightarrow \infty} D\left(x_{n}, F(T)\right)$ exists.

Proof: (1) Let $p \in F(T)$, it follows from (1.1) that

$$
\limsup _{n \rightarrow \infty}\left\{\sup _{x \in E, p \in F(T)}\left\{d\left(T^{n} x, p\right)-d(x, p)\right\}\right\} \leq 0 .
$$

This implies that for any given $\varepsilon>0$, there exists a positive integer $n_{0}$ such that for $n \geq n_{0}$ we have

$$
\sup _{x \in E, p \in F(T)}\left\{d\left(T^{n} x, p\right)-d(x, p)\right\}<\varepsilon .
$$

Since $\left\{x_{n}\right\},\left\{y_{n}\right\},\left\{z_{n}\right\} \subset E$, we have 


$$
\begin{array}{ll}
d\left(T^{n} x_{n}, p\right)-d\left(x_{n}, p\right)<\varepsilon, \quad \forall p \in F(T), \quad \forall n \geq n_{0} \\
d\left(T^{n} y_{n}, p\right)-d\left(y_{n}, p\right)<\varepsilon, \quad \forall p \in F(T), \quad \forall n \geq n_{0} \\
d\left(T^{n} z_{n}, p\right)-d\left(z_{n}, p\right)<\varepsilon, \quad \forall p \in F(T), \quad \forall n \geq n_{0} .
\end{array}
$$

Thus for each $n \geq 0$ and for any $p \in F(T)$, using (1.2) and (2.2), we note that

$$
\begin{aligned}
d\left(x_{n+1}, p\right) & =d\left(W\left(x_{n}, T^{n} y_{n}, u_{n} ; a_{n}, b_{n}, c_{n}\right), p\right) \\
& \leq a_{n} d\left(x_{n}, p\right)+b_{n} d\left(T^{n} y_{n}, p\right)+c_{n} d\left(u_{n}, p\right) \\
& \leq a_{n} d\left(x_{n}, p\right)+b_{n}\left[d\left(y_{n}, p\right)+\varepsilon\right]+c_{n} d\left(u_{n}, p\right) \\
& \leq a_{n} d\left(x_{n}, p\right)+b_{n} d\left(y_{n}, p\right)+b_{n} \varepsilon+c_{n} d\left(u_{n}, p\right)
\end{aligned}
$$

and

$$
\begin{aligned}
d\left(y_{n}, p\right) & =d\left(W\left(x_{n}, T^{n} z_{n}, v_{n} ; a_{n}^{\prime}, b_{n}^{\prime}, c_{n}^{\prime}\right), p\right) \\
& \leq a_{n}^{\prime} d\left(x_{n}, p\right)+b_{n}^{\prime} d\left(T^{n} z_{n}, p\right)+c_{n}^{\prime} d\left(v_{n}, p\right) \\
& \leq a_{n}^{\prime} d\left(x_{n}, p\right)+b_{n}^{\prime}\left[d\left(z_{n}, p\right)+\varepsilon\right]+c_{n}^{\prime} d\left(v_{n}, p\right) \\
& \leq a_{n}^{\prime} d\left(x_{n}, p\right)+b_{n}^{\prime} d\left(z_{n}, p\right)+b_{n}^{\prime} \varepsilon+c_{n}^{\prime} d\left(v_{n}, p\right)
\end{aligned}
$$

and

$$
\begin{aligned}
d\left(z_{n}, p\right) & =d\left(W\left(x_{n}, T^{n} x_{n}, w_{n} ; a_{n}^{\prime \prime}, b_{n}^{\prime \prime}, c_{n}^{\prime \prime}\right), p\right) \\
& \leq a_{n}^{\prime \prime} d\left(x_{n}, p\right)+b_{n}^{\prime \prime} d\left(T^{n} x_{n}, p\right)+c_{n}^{\prime \prime} d\left(w_{n}, p\right) \\
& \leq a_{n}^{\prime \prime} d\left(x_{n}, p\right)+b_{n}^{\prime \prime}\left[d\left(x_{n}, p\right)+\varepsilon\right]+c_{n}^{\prime \prime} d\left(w_{n}, p\right) \\
& \leq\left(a_{n}^{\prime \prime}+b_{n}^{\prime \prime}\right) d\left(x_{n}, p\right)+b_{n}^{\prime \prime} \varepsilon+c_{n}^{\prime \prime} d\left(w_{n}, p\right) \\
& =\left(1-c_{n}^{\prime \prime}\right) d\left(x_{n}, p\right)+b_{n}^{\prime \prime} \varepsilon+c_{n}^{\prime \prime} d\left(w_{n}, p\right) \\
& \leq d\left(x_{n}, p\right)+b_{n}^{\prime \prime} \varepsilon+c_{n}^{\prime \prime} d\left(w_{n}, p\right) .
\end{aligned}
$$

Substituting (2.5) into (2.4), we have

$$
\begin{aligned}
d\left(y_{n}, p\right) \leq & a_{n}^{\prime} d\left(x_{n}, p\right)+b_{n}^{\prime}\left[d\left(x_{n}, p\right)+b_{n}^{\prime \prime} \varepsilon+c_{n}^{\prime \prime} d\left(w_{n}, p\right)\right] \\
& +b_{n}^{\prime} \varepsilon+c_{n}^{\prime} d\left(v_{n}, p\right) \\
\leq & \left(a_{n}^{\prime}+b_{n}^{\prime}\right) d\left(x_{n}, p\right)+b_{n}^{\prime} \varepsilon\left(1+b_{n}^{\prime \prime}\right)+b_{n}^{\prime} c_{n}^{\prime \prime} d\left(w_{n}, p\right)+c_{n}^{\prime} d\left(v_{n}, p\right) \\
\leq & \left(a_{n}^{\prime}+b_{n}^{\prime}\right) d\left(x_{n}, p\right)+b_{n}^{\prime} \varepsilon\left(1+b_{n}^{\prime \prime}\right)+b_{n}^{\prime} c_{n}^{\prime \prime} d\left(w_{n}, p\right)+c_{n}^{\prime} d\left(v_{n}, p\right) \\
\leq & \left(a_{n}^{\prime}+b_{n}^{\prime}\right) d\left(x_{n}, p\right)+2 b_{n}^{\prime} \varepsilon+b_{n}^{\prime} c_{n}^{\prime \prime} d\left(w_{n}, p\right)+c_{n}^{\prime} d\left(v_{n}, p\right) \\
= & \left(1-c_{n}^{\prime \prime}\right) d\left(x_{n}, p\right)+2 b_{n}^{\prime} \varepsilon+b_{n}^{\prime} c_{n}^{\prime \prime} d\left(w_{n}, p\right)+c_{n}^{\prime} d\left(v_{n}, p\right) \\
\leq & d\left(x_{n}, p\right)+2 b_{n}^{\prime} \varepsilon+c_{n}^{\prime \prime} d\left(w_{n}, p\right)+c_{n}^{\prime} d\left(v_{n}, p\right) .
\end{aligned}
$$

Again substituting (2.6) into (2.3), we have 


$$
\begin{aligned}
d\left(x_{n+1}, p\right) \leq & a_{n} d\left(x_{n}, p\right)+b_{n}\left[d\left(x_{n}, p\right)+2 b_{n}^{\prime} \varepsilon+c_{n}^{\prime \prime} d\left(w_{n}, p\right)+c_{n}^{\prime} d\left(v_{n}, p\right)\right] \\
& +b_{n} \varepsilon+c_{n} d\left(u_{n}, p\right) \\
\leq & \left(a_{n}+b_{n}\right) d\left(x_{n}, p\right)+b_{n} \varepsilon\left(1+2 b_{n}^{\prime}\right)+b_{n}\left[c_{n}^{\prime \prime} d\left(w_{n}, p\right)+c_{n}^{\prime} d\left(v_{n}, p\right)\right]+c_{n} d\left(u_{n}, p\right) \\
\leq & \left(a_{n}+b_{n}\right) d\left(x_{n}, p\right)+b_{n}\left[3 \varepsilon+c_{n}^{\prime} d\left(v_{n}, p\right)+c_{n}^{\prime \prime} d\left(w_{n}, p\right)\right]+c_{n} d\left(u_{n}, p\right) \\
= & \left(1-c_{n}\right) d\left(x_{n}, p\right)+b_{n}\left[3 \varepsilon+c_{n}^{\prime} d\left(v_{n}, p\right)+c_{n}^{\prime \prime} d\left(w_{n}, p\right)\right]+c_{n} d\left(u_{n}, p\right) \\
\leq & d\left(x_{n}, p\right)+b_{n}\left[3 \varepsilon+c_{n}^{\prime} d\left(v_{n}, p\right)+c_{n}^{\prime \prime} d\left(w_{n}, p\right)\right]+c_{n} d\left(u_{n}, p\right)
\end{aligned}
$$

since $\left\{v_{n}\right\}$ and $\left\{w_{n}\right\}$ are bounded sequences in $E$, and so $\left\{d\left(v_{n}, p\right)\right\}$ and $\left\{d\left(w_{n}, p\right)\right\}$ are also bounded sequences in $[0, \infty)$. Let

$$
M=3 \varepsilon+\sup _{n \geq 0} d\left(v_{n}, p\right)+\sup _{n \geq 0} d\left(w_{n}, p\right)<\infty .
$$

Therefore

$$
d\left(x_{n+1}, p\right) \leq d\left(x_{n}, p\right)+M b_{n}+c_{n} d\left(u_{n}, p\right), \quad \forall n \geq n_{0}, \quad \forall p \in F(T) .
$$

This completes the proof of part (a).

(b) It follows from conclusion (1) that for any $m \geq 1$, we have

$$
\begin{aligned}
d\left(x_{n+m}, p\right) \leq & d\left(x_{n+m-1}, p\right)+M b_{n+m-1}+c_{n+m-1} d\left(u_{n+m-1}, p\right) \\
\leq & d\left(x_{n+m-2}, p\right)+M b_{n+m-2}+c_{n+m-2} d\left(u_{n+m-2}, p\right) \\
& +M b_{n+m-1}+c_{n+m-1} d\left(u_{n+m-1}, p\right) \\
\leq & d\left(x_{n+m-2}, p\right)+M\left[b_{n+m-1}+b_{n+m-2}\right]+c_{n+m-1} d\left(u_{n+m-1}, p\right) \\
& +c_{n+m-2} d\left(u_{n+m-2}, p\right) \\
\leq & \cdots \\
\leq & \cdots \\
\leq & d\left(x_{n}, p\right)+M \cdot \sum_{k=n}^{n+m-1} b_{k}+\sum_{k=n}^{n+m-1} c_{k} d\left(u_{k}, p\right), \quad \forall n \geq n_{0}, \quad \forall p \in F(T) .
\end{aligned}
$$

This completes the proof of part (b).

(c) Again from conclusion (1), we have

$$
\begin{aligned}
\inf _{q \in F(T)} d\left(x_{n+1}, q\right) & \leq \inf _{q \in F(T)}\left[d\left(x_{n}, q\right)+M b_{n}+c_{n} d\left(u_{n}, p\right)\right] \\
& \leq \inf _{q \in F(T)} d\left(x_{n}, q\right)+M b_{n}+c_{n} d\left(u_{n}, p\right), \quad \forall n \geq n_{0}
\end{aligned}
$$

where $p \in F(T)$ is some given point. Therefore we have 


$$
D\left(x_{n+1}, F(T)\right) \leq D\left(x_{n}, F(T)\right)+M b_{n}+c_{n} d\left(u_{n}, p\right), \quad \forall n \geq n_{0}, \quad p \in F(T) .
$$

By condition (i) and (ii), $\sum_{n=1}^{\infty}\left[M b_{n}+c_{n} d\left(u_{n}, p\right)\right]<\infty$. Hence from Lemma 1.1 we know that the $\lim _{n \rightarrow \infty} D\left(x_{n}, F(T)\right)$ exists. This completes the proof of (c).

Theorem 2.1: Let $(E, d, W)$ be a complete convex metric space, $T: E \rightarrow E$ be an asymptotically quasi-nonexpansive type mapping which satisfies the Lipschitz condition. For any given $x_{0} \in E$, let $\left\{x_{n}\right\}$ be the three-step iterative sequence with errors defined by (1.2). If the sequences $\left\{b_{n}\right\}$ and $\left\{c_{n}\right\}$ appeared in (1.2) satisfying the following conditions:

(i) $\sum_{n=1}^{\infty} b_{n}<\infty$,

(ii) $\sum_{n=1}^{\infty} c_{n}<\infty$.

Then $\left\{x_{n}\right\}$ converges strongly to a fixed point of $T$ in $E$ if and only if

$$
\liminf _{n \rightarrow \infty} D\left(x_{n}, F(T)\right)=0
$$

where $D(y, S)$ denotes the distance from $y$ to the set $S$ i.e. $D(y, S)=\inf _{s \in S} d(y, s)$.

Proof: The necessity is obvious. Now, we prove the sufficiency. Suppose that the condition $\liminf _{n \rightarrow \infty} D\left(x_{n}, F(T)\right)=0$ is satisfied. Then from Lemma 2.1(c) and 1.1, we have

$$
\lim _{n \rightarrow \infty} D\left(x_{n}, F(T)\right)=0 .
$$

First, we will prove that $\left\{x_{n}\right\}$ is a Cauchy sequence $E$. By the conditions $(i),(i i)$ and (2.7), for any given $\varepsilon>0$, there exists a positive integer $n_{1} \geq n_{0}$ (where $n_{0}$ is the positive integer appeared in Lemma 2.1) such that for any $n \geq n_{1}$, we have

$$
D\left(x_{n}, F(T)\right)<\varepsilon
$$

and

$$
\sum_{n=n_{1}}^{\infty} M b_{n}<\varepsilon \quad \text { and } \quad \sum_{k=n_{1}}^{\infty} c_{k} d\left(u_{k}, p\right)<\varepsilon . \quad(2.8)(b)
$$

By the definition of infimum, it follows from (2.8)(a) that for any given $n \geq n_{1}$ there exists an $p(n) \in F(T)$ such that

$$
d\left(x_{n}, p(n)\right)<2 \varepsilon .
$$


On the other hand, it follows from Lemma 2.1 that for the given $\varepsilon>0$ and for any $n \geq n_{1} \geq n_{0}$, we have

$$
\begin{aligned}
d\left(x_{n+m}, x_{n}\right) & \leq d\left(x_{n+m}, p(n)\right)+d\left(x_{n}, p(n)\right) \\
& \leq d\left(x_{n}, p(n)\right)+M \cdot \sum_{k=n}^{n+m-1} b_{k}+\sum_{k=n}^{n+m-1} c_{k} d\left(u_{k}, p\right)+d\left(x_{n}, p(n)\right) \\
& =2 d\left(x_{n}, p(n)\right)+M \cdot \sum_{k=n}^{n+m-1} b_{k}+\sum_{k=n}^{n+m-1} c_{k} d\left(u_{k}, p\right), \quad m \geq 1 .
\end{aligned}
$$

Therefore from (2.8)(a), (2.8)(b) and (2.9) and the above inequality, we have

$$
d\left(x_{n+m}, x_{n}\right)<4 \varepsilon+\varepsilon+\varepsilon=6 \varepsilon, \quad m \geq 1 .
$$

This implies that $\left\{x_{n}\right\}$ is a Cauchy sequence in $E$. Since $E$ is complete, there exists $p^{*} \in E$ such that $x_{n} \rightarrow p^{*}$ as $n \rightarrow \infty$.

Now, we will prove that $p^{*}$ is a fixed point of $T$ in $E$.

Since $x_{n} \rightarrow p^{*}$ and $D\left(x_{n}, F(T)\right) \rightarrow 0$ as $n \rightarrow \infty$, for given $\varepsilon>0$, there exists a positive integer $n_{2} \geq n_{1} \geq n_{0}$ such that for $n \geq n_{2}$, we have

$$
d\left(x_{n}, p^{*}\right)<\varepsilon \quad \text { and } \quad D\left(x_{n}, F(T)\right)<\varepsilon .
$$

It follows from the second inequality in (2.10) that there exists $q \in F(T)$ such that

$$
d\left(x_{n_{2}}, q\right)<2 \varepsilon
$$

Moreover, it follows from equation (2.1) that for any $n \geq n_{2}$, we have

$$
d\left(T^{n} p^{*}, q\right)-d\left(p^{*}, q\right)<\varepsilon .
$$

Therefore from (2.10)-(2.12), for any $n \geq n_{2}$, we have

$$
\begin{aligned}
d\left(T^{n} p^{*}, p^{*}\right) & \leq d\left(T^{n} p^{*}, q\right)+d\left(p^{*}, q\right) \\
& \leq d\left(p^{*}, q\right)+\varepsilon+d\left(p^{*}, q\right) \\
& =\varepsilon+2 d\left(p^{*}, q\right) \\
& \leq \varepsilon+2\left[d\left(p^{*}, x_{n_{2}}\right)+d\left(x_{n_{2}}, q\right)\right] \\
& <\varepsilon+2(\varepsilon+2 \varepsilon)=7 \varepsilon .
\end{aligned}
$$


This implies that

$$
T^{n} p^{*} \rightarrow p^{*} \quad \text { as } \quad n \rightarrow \infty
$$

Again since for any $n \geq n_{2}$, we have

$$
\begin{aligned}
d\left(T^{n} p^{*}, T p^{*}\right) & \leq d\left(T^{n} p^{*}, q\right)+d\left(T p^{*}, q\right) \\
& \leq d\left(p^{*}, q\right)+\varepsilon+d\left(T p^{*}, q\right) \\
& \leq d\left(p^{*}, q\right)+\varepsilon+L d\left(p^{*}, q\right) \\
& \leq d\left(p^{*}, x_{n_{2}}\right)+d\left(x_{n_{2}}, q\right)+\varepsilon+L\left[d\left(p^{*}, x_{n_{2}}\right)+d\left(x_{n_{2}}, q\right)\right] \\
& <\varepsilon+2 \varepsilon+\varepsilon+L(\varepsilon+2 \varepsilon) \\
& =4 \varepsilon+L(3 \varepsilon) .
\end{aligned}
$$

This shows that $T^{n} p^{*} \rightarrow T p^{*}$ as $n \rightarrow \infty$. From the uniqueness of limit, we have $p^{*}=T p^{*}$. This completes the proof.

From Theorem 2.1 we can easily obtain the following theorem:

Theorem 2.2: Let $(E, d, W)$ be a complete convex metric space, $T: E \rightarrow E$ be an asymptotically nonexpansive mapping with $F(T) \neq \emptyset$. Let $\left\{x_{n}\right\}$ be the three-step iterative sequence with errors defined by (1.2) satisfying the conditions (i) and (ii) in Theorem 2.1. Then $\left\{x_{n}\right\}$ converges strongly to a fixed point $T$ if and only if

$$
\liminf _{n \rightarrow \infty} D\left(x_{n}, F(T)\right)=0
$$

Proof: In order to prove Theorem 2.2, it is sufficient to show that all conditions in Theorem 2.1 are satisfied. Since $T$ is asymptotically nonexpansive with $F(T) \neq \emptyset$, there exists a sequence $\left\{k_{n}\right\} \subset[1, \infty)$ with $\lim _{n \rightarrow \infty} k_{n}=1$ such that

$$
d\left(T^{n} x, p\right) \leq k_{n} d(x, p), \quad \forall p \in F(T), \quad \forall x \in E, \quad n \geq 1
$$

Taking $n=1$ and $L=k_{1}$, we have

$$
d(T x, p) \leq L d(x, p), \quad \forall p \in F(T), \quad \forall x \in E .
$$

This implies that the condition Lipschitz is satisfied. On the other hand, from (2.13) we have

$$
d\left(T^{n} x, p\right)-k_{n} d(x, p) \leq 0, \quad \forall p \in F(T), \quad \forall x \in E, \quad n \geq 1
$$

Therefore we have 


$$
\limsup _{n \rightarrow \infty}\left\{\sup _{x \in E, p \in F(T)}\left\{d\left(T^{n} x, p\right)-d(x, p)\right\}\right\} \leq 0 .
$$

This implies that $T: E \rightarrow E$ is an asymptotically quasi-nonexpansive type mapping. Therefore all conditions in Theorem 2.1 are satisfied. The conclusion of Theorem 2.2 can be obtained from Theorem 2.1 immediately.

By using the same method in Theorem 2.1, we can easily obtain the following theorem.

Theorem 2.3: Let $(E, d, W)$ be a complete convex metric space, $T: E \rightarrow E$ be a quasi-nonexpansive mapping. Let $\left\{x_{n}\right\}$ be the three-step iterative sequence with errors defined by (1.2) satisfying the conditions (i) and (ii) in Theorem 2.1. Then $\left\{x_{n}\right\}$ converges strongly to a fixed point $T$ if and only if

$$
\liminf _{n \rightarrow \infty} D\left(x_{n}, F(T)\right)=0 .
$$

From Theorem 2.1, we can also obtain the following:

Theorem 2.4: Let $E$ be a Banach space and $T: E \rightarrow E$ be an asymptotically quasi-nonexpansive type mapping which satisfies Lipschitz condition. Let $\left\{x_{n}\right\}$ be the three-step iterative sequence with errors defined by

$$
\begin{gathered}
x_{0} \in E, \\
x_{n+1}=a_{n} x_{n}+b_{n} T^{n} y_{n}+c_{n} u_{n}, \\
y_{n}=a_{n}^{\prime} x_{n}+b_{n}^{\prime} T^{n} z_{n}+c_{n}^{\prime} v_{n}, \\
z_{n}=a_{n}^{\prime \prime} x_{n}+b_{n}^{\prime \prime} T^{n} x_{n}+c_{n}^{\prime \prime} w_{n}, \quad n \geq 0
\end{gathered}
$$

where $\left\{u_{n}\right\},\left\{v_{n}\right\}$ and $\left\{w_{n}\right\}$ are three bounded sequences in $E$ and $\left\{a_{n}\right\},\left\{b_{n}\right\}$, $\left\{c_{n}\right\},\left\{a_{n}^{\prime}\right\},\left\{b_{n}^{\prime}\right\},\left\{c_{n}^{\prime}\right\},\left\{a_{n}^{\prime \prime}\right\},\left\{b_{n}^{\prime \prime}\right\}$, and $\left\{c_{n}^{\prime \prime}\right\}$ are the nine sequences in [0,1] satisfying $a_{n}+b_{n}+c_{n}=a_{n}^{\prime}+b_{n}^{\prime}+c_{n}^{\prime}=a_{n}^{\prime \prime}+b_{n}^{\prime \prime}+c_{n}^{\prime \prime}=1, \forall n \geq 0$ and $\sum_{n=1}^{\infty} b_{n}<\infty$, $\sum_{n=1}^{\infty} c_{n}<\infty$. Then $\left\{x_{n}\right\}$ converges strongly to a fixed point of $T$ in $E$ if and only if

$$
\liminf _{n \rightarrow \infty} D\left(x_{n}, F(T)\right)=0 .
$$

Proof: Since $E$ is a Banach space, it is a complete convex metric space with a convex structure $W(x, y, z ; \alpha, \beta, \gamma):=\alpha x+\beta y+\gamma z$, for all $x, y, z \in E$ and for all $\alpha, \beta, \gamma \in[0,1]$ with $\alpha+\beta+\gamma=1$. Therefore, the conclusion of Theorem 2.4 can be obtained from Theorem 2.1 immediately.

Remark 2.2: (1) We would like to point out that Theorem 2.1, 2.2 and 2.3 of this paper generalize and improve the corresponding results of Liu [12]- [14], 
Petryshyn and Williamson [16], Tan and Xu [20], Ghosh and Debnath [6] and Chang [1]- [3]. Our results also contain the corresponding results of [1]- [6], [12][16], 4], [18] as its special cases. Especially Theorem 2.4 generalizes and improves the result of Liu [14] in the following aspects:

(i) The condition that " $E$ is a compact subset of a uniformly convex Banach space" is removed. We only assume that $E$ is a general Banach space.

(ii) The asymptotically quasi-nonexpansive mapping in [14] is extended to asymptotically quasi-nonexpansive type mapping.

(iii) The condition " $(L, \alpha)$-uniformly Lipschitz" in [14 is replaced by "Lipschitz" which is more weaker than above.

(iv) The two-step iteration scheme is extended to three-step iteration scheme.

(2) Our results also extend and improve the corresponding results of Kim et al. [10] to the case of more general class of asymptotically quasi-nonexpansive mappings.

(3) Our results also extend the corresponding results of Chang et al. [4] to the case of $(L, 1)$-Lipschitz asymptotically quasi-nonexpansive type mapping and three-step iteration scheme.

\section{REFERENCES}

1. S.S. Chang, Some results for asymptotically pseudo-contractive mapping and asymptotically nonexpansive mappings, Proc. Amer. Math. Soc. 129(3) (2001), 845-853. (document), 1, 2

2. S.S. Chang, Iterative approximation problem of fixed points for asymptotically nonexpansive mappings in Banach spaces, Acta Math. Appl. 24(2) (2001), 236-241. (document), 1

3. S.S. Chang, On the approximating problem of fixed points for asymptotically nonexpansive mappings, Indian J. Pure and Appl. 32(9) (2001), 1-11. (document), 1, 2

4. S.S. Chang, J.K. Kim and D.S. Jin, Iterative sequences with errors for asymptotically quasinonexpansive type mappings in convex metric spaces, Archives of Inequality and Applications 2 (2004), 365-374. 1, 2

5. Y.J. Cho, H. Zhou and G. Guo, Weak and strong convergence theorems for three step iterations with errors for asymptotically nonexpansive mappings, Computers and Math. with Appl. 47 (2004), 707-717. 1

6. M.K. Ghosh and L. Debnath, Convergence of Ishikawa iterates of quasi-nonexpansive mappings, J. Math. Anal. Appl. 207 (1997), 96-103. (document), 1, 2

7. R. Glowinski and P. Le Tallec, Augmented Lagrangian Operator-Splitting Metods in Nonlinear Mechanics, SIAM, Philadelphia (1989). 1

8. K. Goebel and W.A. Kirk, A fixed point theorem for asymptotically nonexpansive mappings, Proc. Amer. Math. Soc. 35 (1972), 171-174. 
9. J.K. Kim, K.H. Kim and K.S. Kim, Convergence theorems of modified three-step iterative sequences with mixed errors for asymptotically quasi-nonexpansive mappings in Banach spaces, PanAmerican Math. Jour. 14(1) (2004), 45-54. (document)

10. J.K. Kim, K.H. Kim and K.S. Kim, Three-step iterative sequences with errors for asymptotically quasi-nonexpansive mappings in convex metric spaces, Nonlinear Anal. Convex Anal. RIMS Vol. 1365 (2004), pp. 156-165. (document), 1, 2

11. W.A. Kirk, Fixed point theorems for non-lipschitzian mappings of asymptotically nonexpansive type, Israel J. Math. 17 (1974), 339-346.

12. Q.H. Liu, Iterative sequences for asymptotically quasi-nonexpansive mappings, J. Math. Anal. Appl. 259 (2001), 1-7. (document), 1, 2

13. Q.H. Liu, Iterative sequences for asymptotically quasi-nonexpansive mappings with error member, J. Math. Anal. Appl. 259 (2001), 18-24. (document), 1

14. Q.H. Liu, Iterative sequences for asymptotically quasi-nonexpansive mappings with error member of uniformly convex Banach spaces, J. Math. Anal. Appl. 266 (2002), 468-471. (document), 1, 2

15. M.A. Noor, New approximation schemes for general variational inequalities, J. Math. Anal. Appl. 251 (2000), 217-229. 1

16. W.V. Petryshyn and T.E. Williamson, Strong and weak convergence of the sequence of successive approximations for quasi-nonexpansive mappings, J. Math. Anal. Appl. 43 (1973), 459-497. (document), 1, 2

17. W. Takahashi, A convexity in metric space and nonexpansive mappings I, Kodai Math. Sem. Rep. 22 (1970), 142-149. 1

18. B.L. Xu and M.A. Noor, Fixed point iterations for asymptotically nonexpansive mappings in Banach spaces, J. Math. Anal. Appl. 267 (2002), No.2, 444-453. (document), 1, 2

19. K.K. Tan and H.K. Xu, Approximating fixed points of nonexpansive mappings by the Ishikawa iteration process, J. Math. Anal. Appl. 178 (1993), 301-308. 1

20. K.K. Tan and H.K. Xu, Fixed point iteration processes for asymptotically nonexpansive mappings, Proc. Amer. Math. Soc. 122 (1994), 733-739. (document), 1, 2

Department of Mathematics \& Information Technology, Govt. Nagarjun P.G. College of Science, RAIPUR (C.G.), INDIA.

E-mail address: saluja_1963@rediffmail.com 